\title{
Medicamenteuze behandeling van de overactieve blaas: het heden en de toekomst
}

\author{
L. P. W. Witte · Martin C. Michel
}

Geaccepteerd op: 5 juli 2021 / Published online: 9 augustus 2021

(C) The Author(s) 2021

Samenvatting Muscarine-receptorantagonisten en de $\beta_{3}$-agonist mirabegron vormen de basis van de medicamenteuze behandeling van het overactieveblaassyndroom $(\mathrm{OAB})$. De effectiviteit van muscarine-receptorantagonisten en mirabegron is vergelijkbaar en de combinatie solifenacine en mirabegron is minimaal effectiever dan dezelfde middelen als monotherapie. De bijwerkingen van antimuscarinica zijn onder andere een droge mond en obstipatie en die van mirabegron zijn vergelijkbaar met placebo. Weinig patiënten gebruiken deze middelen langdurig vanwege een gebrek aan effectiviteit ervan en vanwege de bijwerkingen. Er lijken op dit moment geen middelen met een nieuw werkingsmechanisme in ontwikkeling te zijn en de kans is klein daar op korte termijn verandering in komt. Omdat $\mathrm{OAB}$ een symptoomcomplex is, met mogelijk verschillende onderliggende pathologieën en symptoomcombinaties, is het onwaarschijnlijk dat nieuwe middelen duidelijk effectiever zullen zijn. De belangrijkste prioriteiten voor de toekomst zijn niet alleen de ontdekking van nieuwe therapeutische targets, maar ook identificatie van subgroepen met dezelfde symptomatologie of onderliggende pathologie. Biomarkers zouden een rol kunnen spelen bij deze zoektocht.

Trefwoorden overactieve blaas $\cdot$ medicatie . effectiviteit · bijwerkingen

Dr. L. P. W. Witte $(\bowtie)$

afdeling Urologie, Isala Klinieken, Zwolle, Nederland

l.p.w.witte@isala.nl

Prof. dr. M. C. Michel

afdeling Farmacologie, Johannes Gutenberg Universiteit, Mainz, Duitsland

\section{Medical treatment of overactive bladder: the present and the future}

Abstract Muscarinic receptor antagonists and the $\beta_{3}$-agonist mirabegron form the basis of the drug treatment of the overactive bladder syndrome (OAB). The efficacy of muscarinic receptor antagonists and mirabegron are comparable and the combination of solifenacin and mirabegron is moderately more effective than either monotherapy. The side effects of antimuscarinics include dry mouth and constipation and those of mirabegron are similar to placebo. Few patients use these drugs for a longer time due to lack of efficacy and side-effects. No potential drugs with new mechanisms of action seem to be in clinical trials at the moment and there is little chance that this will change in the short term. Because $\mathrm{OAB}$ is a symptom complex, with possibly several underlying pathologies and various combinations of symptoms, it is unlikely that new agents will be significantly more effective. The main priorities for the future are not only the discovery of new therapeutic agents, but also identification of subgroups with the same symptomatology or underlying pathology. Biomarkers could play a role in this search.

Keywords overactive bladder - medication · efficacy · tolerance

\section{Introductie}

Muscarine-receptorantagonisten en de $\beta_{3}$-agonist mirabegron vormen al jaren de basis van de medicamenteuze behandeling van het overactieveblaassyndroom (OAB). Ondanks overtuigend bewijs van de effectiviteit van muscarine-receptorantagonisten en mirabegron in placebogecontroleerde studies, blijven maar weinig patiënten deze middelen langdurig gebruiken. 
Tabel 1 Effectiviteit van OAB-medicatie in de dagelijkse praktijk

\begin{tabular}{|c|c|c|c|c|c|}
\hline medicatie & $n$ & urgency & incontinentie & frequency & nycturie \\
\hline darifenacine & 3.766 & $-45 \%$ & $-38 \%$ & $-35 \%$ & $-45 \%$ \\
\hline solifenacine & 4.450 & $-58 \%$ & $-53 \%$ & $-41 \%$ & $-54 \%$ \\
\hline tolterodine & 2.250 & $-75 \%$ & $-75 \%$ & $-38 \%$ & $\mathrm{nb}$ \\
\hline tolterodine & 3.824 & $-80 \%$ & $-79 \%$ & $-46 \%$ & $-59 \%$ \\
\hline mirabegron & 774 & $-52 \%$ & $-53 \%$ & $-34 \%$ & $-49 \%$ \\
\hline
\end{tabular}

Data van in Duitsland uitgevoerde observationele studies. Percentages betreffen de reductie ten opzichte van baseline. Bron: Met aanpassingen overgenomen uit [3]

$O A B$ overactieve blaas, $n b$ niet beschikbaar

De belangrijkste redenen hiervoor zijn gebrek aan effectiviteit en de bijwerkingen, maar ook niet vervulde, misschien onrealistische verwachtingen. Er is dus een duidelijke behoefte aan middelen die effectiever zijn en beter verdragen worden dan de huidige beschikbare medicatie.

In dit artikel zullen we een overzicht geven van de middelen die nu tot onze beschikking staan (het heden) en zullen we de context bespreken waarbinnen de ontwikkeling van nieuwe OAB-geneesmiddelen plaats moet vinden (de toekomst).

\section{Het heden}

\section{Effectiviteit}

\section{Muscarine-receptorantagonisten}

De effectiviteit van alle in Nederland beschikbare muscarine-antagonisten is statistisch significant beter dan van placebo in gerandomiseerde en gecontroleerde onderzoeken [1]. Echter, de grootte van het effect is matig volgens een meta-analyse; de gemiddelde afname per dag van incontinentie-episodes en mictiefrequentie is slechts $<1$ en $<1,2$ respectievelijk [1]. De effectiviteit van muscarine-antagonisten in observationele studies is veel groter, namelijk een afname van aandrangsincontinentie van 38-79\% en een afname van frequency van $34-41 \%$ (tab. 1). Mogelijke verklaringen voor de verschillen in uitkomsten tussen gecontroleerde en observationele studies zijn de sterk gecontroleerde en kunstmatige setting van een placebogecontroleerde studie en de placebo-inloopperiode voorafgaand aan de actieve behandeling, waardoor mogelijk al verbetering van symptomen optreedt. Een ander probleem is dat niet alle symptomen die bij $\mathrm{OAB}$ horen, zoals urgency, frequency, aandrangsincontinentie en nycturie, in dezelfde mate afnemen na behandeling. De effecten op aandrangsincontinentie en frequency zijn in sommige observationele studies veel groter dan de effecten op urgency en nycturie [2]. In de meeste onderzoeken hebben muscarineantagonisten zelfs helemaal geen effect op nycturie in vergelijking met placebo [3].

\section{$\beta_{3}$-adrenoceptoragonisten}

Hoewel er een duidelijk klasse-effect is van muscarine-antagonisten, geldt dit niet voor $\beta_{3}$-adrenoceptoragonisten. Mirabegron is in veel onderzoeken consequent effectiever dan placebo [4], maar andere $\beta_{3}$ agonisten zijn dat niet. Als voorbeeld geldt ritobegron, dat het primaire eindpunt in de enige fase III-studie niet bereikt heeft [5]. Vibegron was effectief in vergelijking met placebo in meerdere fase III-onderzoeken $[6,7]$ en voor solabegron bestaan op dit moment alleen resultaten van fase II-onderzoeken [8].

Hoewel mirabegron effectief is bij sommige patiënten die onvoldoende reageren op een muscarineantagonist, is de werkzaamheid van mirabegron in de totale groep van OAB-patiënten vergelijkbaar met die van muscarine-antagonisten [9]. Deze bevinding was enigszins verrassend, omdat $\beta_{3}$-adrenoceptoragonisten, in tegenstelling tot muscarine-antagonisten, ook werken tegen contractie die veroorzaakt wordt door andere mediatoren, zoals histamine of bradykinine $[10,11]$. Hierdoor werd verwacht dat $\beta_{3}$-adrenoceptoragonisten juist effectiever zouden zijn dan muscarineantagonisten. Een andere mogelijke verklaring voor de tegenvallende klinische effectiviteit van $\beta_{3}$-adrenoceptoragonisten is desensitisatie. Bij desensitisatie vindt downregulatie plaats van receptoren, waardoor het klinische effect van een middel kan afnemen. Dit proces treedt typisch op bij gebruik van agonisten en minder vaak bij antagonisten. Hoewel aanvankelijk werd aangenomen dat $\beta_{3}$-adrenoceptoren resistent waren tegen desensitisatie, is het nu duidelijk dat deze receptoren in sommige weefsels en celtypen, desensitisatie kunnen ondergaan [3]; of dit in vivo ook van toepassing is op de menselijke blaas, blijft onduidelijk. Net als bij muscarine-antagonisten was de werkzaamheid van mirabegron ten opzichte van placebo slechts matig in gecontroleerde onderzoeken [4], maar aanzienlijk groter in een observationeel onderzoek [12].

\section{Solifenacine plus mirabegron}

De combinatie van anticholinergica en mirabegron ligt voor de hand om de effectiviteit te verhogen zonder toename van de antimuscarinerge bijwerkingen die optreden bij dosisverhoging van muscarine-antagonisten. In twee fase III-studies bleek de combinatie solifenacine $5 \mathrm{mg}+$ mirabegron $50 \mathrm{mg}$ matig effectiever dan mirabegron $50 \mathrm{mg}$ monotherapie en solifenacine $5 \mathrm{mg}$ monotherapie na 3 maanden [13] en na 12 maanden [14]. De antimuscarinerge bijwerkingen van de combinatie solinenacine $5 \mathrm{mg}+$ mirabegron $50 \mathrm{mg}$ waren minimaal hoger dan van solifenacine $5 \mathrm{mg}$ monotherapie na 3 maanden [13], maar niet verschillend na 12 maanden [14]. De combinatie heeft dus een matig betere effectiviteit, maar vergelijkbare bijwerkingen als solifenacine $5 \mathrm{mg}$ monotherapie. 


\section{Andere farmacologische targets}

Fosfodiësterase-type 5-remmers (PDE-5 remmers) worden vooral gebruikt voor de behandeling van erectiele disfunctie (ED), maar zijn ook getest bij mannen met ED en LUTS en lijken ook actief bij OAB [15]. Vanwege de hoge expressie in de blaas is PDE-5 een interessant target voor OAB-behandeling, maar de placebogecontroleerde studies zijn te beperkt om er duidelijke conclusies uit te kunnen trekken [15]. Andere potentiële targets voor de behandeling van $\mathrm{OAB}$ zijn al langer geleden onderzocht, maar zijn niet verder ontwikkeld, ondanks veelbelovende resultaten in fase II-onderzoeken, zoals de studie naar het effect van cizolirtinecitraat, een calcitonine gengerelateerde peptide-receptorantagonist [16]. Andere middelen, zoals kaliumkanaalmodulatoren zijn in het verleden onderzocht, maar faalden in klinische onderzoeken vanwege beperkte effectiviteit [17] of slechte tolerantie [18]. Rho-kinaseremmers zijn in sommige landen wel ontwikkeld voor andere indicaties, maar nog niet voor OAB [19]. Daarnaast zijn er enkele targets die op dit moment preklinisch worden onderzocht, zoals neurokinine-receptoren [20] en stikstofoxidesynthase/guanylyl cyclase [21], receptoren die horen bij de familie van de transient receptor potential (TRPV1, TRPV4, TRPA1, TRPM4 en TRPM8)ionenkanalen [22] en componenten van het endocannabinoïde systeem, zoals vetzuuramidehydrolase [23]. Fase II- of III-onderzoeken zijn echter niet gaande op dit moment.

Samenvattend, er zijn veelbelovende targets en stoffen beschikbaar, maar de ontwikkeling hiervan is gestagneerd, soms om onduidelijke redenen. Daarom zijn er in de komende jaren weinig nieuwe middelen te verwachten.

\section{Tolerantie en bijwerkingen}

\section{Muscarine-receptorantagonisten}

Goede veiligheid en tolerantie zijn belangrijke eigenschappen van medicijnen die gebruikt worden bij de behandeling van niet-levensbedreigende aandoeningen, zoals OAB. Hoewel de meeste muscarine-antagonisten over het algemeen goed verdragen worden, zijn de bijwerkingen toch de voornaamste reden om medicatie te staken [24]. De meest bekende bijwerkingen zijn natuurlijk een droge mond [1], obstipatie, gevolgd door een verhoogd hartritme [24] en negatieve effecten op het centraal zenuwstelsel, zoals cognitieve achteruitgang en slaapstoornissen $[3,25]$. De cognitieve bijwerkingen kunnen niet los gezien worden van de antimuscarinic load, waarmee bedoeld wordt de totale hoeveelheid aan antimuscarine-rge medicatie of medicatie met antimuscarine-rge effecten die een patiënt gebruikt [3].

\section{$\beta_{3}$-agonisten}

Mirabegron heeft hetzelfde bijwerkingenprofiel als placebo [26] en geeft minder vaak een droge mond dan tolterodine [27] in direct vergelijkende onderzoeken. De problemen met een verhoogde bloeddruk kwamen echter pas aan het licht in post-marketing surveillance studies en niet in eerdere fase III- of IVstudies. Gevallen van een hypertensieve crisis met cerebrovasculaire en cardiale gevolgen hebben geleid tot een waarschuwing voor gebruik van mirabegron in stadium 2-hypertensie (systolisch >140 $\mathrm{mm} \mathrm{Hg}$, diastolisch $>90 \mathrm{mmHg}$ ). Het is onduidelijk of deze bijwerkingen alleen voor mirabegron gelden of voor alle $\beta_{3}$-agonisten [28].

\section{De toekomst}

Er bestaat een duidelijke behoefte aan nieuwe medicatie voor de behandeling van $\mathrm{OAB}$ met een betere effectiviteit en minder bijwerkingen. Enkele potentiële OAB-geneesmiddelen hebben nooit het stadium van een bruikbaar medicijn gehaald: ze zijn niet verder onderzocht ondanks veelbelovende fase II-studies [16], werden niet goed genoeg getolereerd [18] of bleken niet effectief in klinische studies [17].

Op dit moment worden er, voor zover publiekelijk bekend, geen klinische fase II- of III-studies uitgevoerd naar de hiervoor genoemde targets. De tegenvallende pijplijn van nieuwe OAB-medicatie is niet los te zien van de context waarbinnen deze medicatie ontwikkeld moet worden.

\section{Interesse van de farmaceutische industrie}

Vanuit commercieel perspectief is het voor farmaceuten niet aantrekkelijk andere muscarine-antagonisten of $\beta_{3}$-agonisten te ontwikkelen, omdat de muscarineantagonisten inmiddels generieke geneesmiddelen geworden zijn en hetzelfde voor mirabegron zal gelden over een paar jaar. Om als kosteneffectief beschouwd te worden door regulerende instanties, zoals het National Institute for Health and Care Excellence in het Verenigd Koninkrijk of het College ter Beoordeling van Geneesmiddelen in Nederland, en dus voor aantrekkelijke vergoeding in aanmerking te komen, moet de effectiviteit van een nieuw OAB-medicijn aanzienlijk beter zijn dan van de huidige generieke muscarine-antagonisten of mirabegron. Het is niet te verwachten dat nieuwe middelen uit deze geneesmiddelenklassen effectiever zullen zijn of minder bijwerkingen zullen hebben dan de reeds beschikbare middelen.

Ondanks de behoefte aan nieuwe medicatie voor $\mathrm{OAB}$, is het onwaarschijnlijk dat nieuwe geneesmiddelenklassen voor OAB zullen worden ontwikkeld zonder de tussenkomst van de farmaceutische industrie. Bijna 98\% van de placebogecontroleerde studies naar muscarine-antagonisten zijn gesponsord door de farmaceutische industrie. Vanwege de hoge kosten is het bijna onmogelijk om zonder grote farmaceuten een nieuw medicijn te ontwikkelen tot en met goedkeuring door de Amerikaanse Food and Drug Administra- 
tion of de in Amsterdam gezetelde European Medicines Agency [3].

\section{Specifieke symptomen en specifieke subgroepen patiënten}

$\mathrm{OAB}$ werd in 2002 gedefinieerd door de International Continence Society (ICS) als 'urgency, met of zonder aandrangsincontinentie, vaak gepaard gaande met frequency en nycturie'. Deze definitie is in de loop van de tijd aangepast, maar alle versies zijn consequent gericht op de aanwezigheid van urgency [29, $30]$. Het ontwerp van de klinische studies voor $\mathrm{OAB}$ is echter grotendeels bepaald door de primaire eindpunten die door de regulerende instanties zijn vastgesteld, namelijk frequency en incontinentie, en niet urgency en nycturie. Er is dus een discrepantie tussen de ICS-definitie van $\mathrm{OAB}$, waarin urgency voorop staat en de primaire eindpunten van de klinische studies, zoals frequency en aandrangsincontinentie. Deze discrepantie kan een verklaring zijn voor de teleurstellende effectiviteit van OAB-medicatie in de dagelijkse praktijk, omdat aan de verwachtingen van patiënten, namelijk de vermindering van urgency, niet voldaan wordt. In het geval van nycturie speelt de multifactoriële etiologie een rol, waarbij niet-urologische oorzaken belangrijker zijn dan alleen $\mathrm{OAB}$ [3].

Daarnaast is OAB een symptoomcomplex, wat impliceert dat $\mathrm{OAB}$ het gevolg kan zijn van uiteenlopende pathologieën. Bovendien presenteert de totale groep OAB-patiënten zich met een heterogeen symptoombeeld; zo is de correlatie van verschillende OABsymptomen tussen patiënten matig, met mogelijke uitzondering van urgency en frequency overdag [30, 31]. De vraag is of het haalbaar is dat nieuwe geneesmiddelen een hogere effectiviteit zullen hebben op alle vier de OAB-symptomen (urgency, aandrangsincontinentie, frequentie en nycturie) in een populatie met mogelijk verschillende onderliggende pathologieën.

Een mogelijke oplossing voor dit probleem is de focus op één symptoom in plaats van op de algemene symptomatologie van $\mathrm{OAB}$. Een andere mogelijkheid is om de zoektocht naar betere medicatie te concentreren op subgroepen OAB-patiënten met een specifieke onderliggende pathologie. Echter, voor de PDE5 -remmers en cizolirtine, die beide effectief en veilig waren in fase II-onderzoeken, bleken geen specifieke subgroepen te zijn met een betere respons [3]. Een voorbeeld van een vergelijkbare en succesvolle strategie is de vasopressine-receptoranaloog desmopressine, die effectiever bleek in het verminderen van nycturie bij patiënten met nachtelijke polyurie.

\section{Conclusie}

Er is behoefte aan medicamenteuze behandelingen van $\mathrm{OAB}$ met een betere effectiviteit en betere tolerantie dan de huidige beschikbare medicatie. Echter, het is onwaarschijnlijk dat dit bereikt kan worden met de op dit moment beschikbare potentiële geneesmiddelen. Er is het meest behoefte aan verbetering van medicatie die is gericht op de specifieke OAB-symptomen urgency en nycturie. De belangrijkste prioriteiten voor de toekomst op het gebied van medicamenteuze behandeling van $O A B$ zijn niet alleen de ontdekking van nieuwe potentiële therapeutische targets, maar ook de identificatie van subgroepen met dezelfde symptomatologie of onderliggende pathologie. Biomarkers zouden een rol kunnen spelen bij deze zoektocht.

Open Access This article is distributed under the terms of the Creative Commons Attribution 4.0 International License (http://creativecommons.org/licenses/by/4.0/), which permits unrestricted use, distribution, and reproduction in any medium, provided you give appropriate credit to the original author(s) and the source, provide a link to the Creative Commons license, and indicate if changes were made.

\section{Literatuur}

1. Michel MC, Murgas S, Oelke M, Schneider T. Evidencebased management of overactive bladder patients: expectation to become symptom-free. Neurourol Urodyn. 2018;37(Suppl5):S401-S2.

2. Michel MC. Where will the next generation of medical treatments for overactive bladder syndrome come from? Int JUrol. 2020;27(4):289-94.

3. Chapple CR, Cardozo L, Nitti VW, Siddiqui E, Michel MC. Mirabegron in overactive bladder: a review of efficacy, safety, and tolerability. Neurourol Urodyn. 2014;33:17-30.

4. Michel MC, Korstanje C. $\beta 3$-Adrenoceptor agonists for overactive bladder syndrome: role of translational pharmacology in a re-positioning drug development project. PharmacolTher. 2016;159:66-82.

5. Staskin D, Frankel J, Varano S, Shortino D, Jankowich R, Mudd PN. International phase III, randomized, doubleblind, placebo and active controlled study to evaluate the safety and efficacy of vibegron in patients with symptoms of overactivebladder: EMPOWUR. JUrol. 2020;204(2):316-24.

6. Yoshida M, Takeda M, Gotoh M, NagaiS, Kurose T. Vibegron, a novel potent and selective b3-adrenoreceptor agonist, for the treatment of patients with overactive bladder: a randomized, double-blind, placebo-controlled phase 3 study. Eur Urol. 2018;73:783-90.

7. Ohlstein EH, KeitzA von, Michel MC.A multicenter, doubleblind, randomized, placebo controlled trial of the $\beta 3$ adrenoceptor agonist solabegron for overactive bladder. Eur Urol. 2012;62:834-40.

8. Maman K, Aballea S, Nazir J, et al. Comparative efficacy and safety of medical treatments for the management of overactive bladder: a systematic literature review and mixed treatment comparison. Eur Urol. 2014;65:755-65.

9. Michel MC, Sand C. Effect of pre-contraction on $\beta$-adrenoceptor-mediated relaxation of rat urinary bladder. World J Urol. 2009;27:711-5.

10. Cernecka H, Sand C, Michel MC. The odd sibling: features of $\beta 3$-adrenoceptor pharmacology. Mol Pharmacol. 2014;86:479-84.

11. Hampel C, Betz D, Burger M, Nowak C, Vogel M. Solifenacin in the elderly: results of an observational study measuring efficacy, tolerability and cognitive effects. Urol Int. 2017;98:350-7. 
12. HerschornS, ChappleCR,AbramsP, etal. Efficacyand safety of combinations of mirabegron and solifenacin compared with monotherapy and placebo in patients with overactive bladder (SYNERGY study). BJU Int. 2017;120(4):562-75.

13. Gratzke C, Maanen R van, Chapple C, et al. Long-term safety and efficacy of mirabegron and solifenacin in combination compared with monotherapy in patients with overactive bladder: a randomised, multicentre phase 3 study (SYNERGYII). Eur Urol. 2018;74(4):501-9.

14. Chughtai B, Ali A, Dunphy C, Kaplan SA. Effect of phosphodiesterase inhibitors in the bladder. Asian J Urol. 2015;2:33-7.

15. Zatura F, Vsetica J, Abdias M, et al. Cizolirtine citrate is safe and effective for treating urinaryincontinence secondary to overactive bladder: a phase 2 proof-of-concept study. Eur Urol. 2010;57:145-52.

16. Chapple CR, Patroneva A, Raines SR. Effect of an ATP-sensitive potassium channel opener in subjects with overactive bladder: a randomized, double-blind, placebo-controlled study. Eur Urol. 2006;49:879-86.

17. Michel MC, Radziszeswski P, Falconer C, MarschallKehrel D, Blot K. Unexpected frequent hepatotoxicity of a prescription drug, flupirtine, marketed for about 30 years. Br J Clin Pharmacol. 2012;73:821-5.

18. Peters SLM, Schmidt M, Michel MC. Rho kinase: a target for treating urinary bladder dysfunction? Trends Pharmacol Sci. 2006;27:492-7.

19. Quinn T, Collins C, Baird AW. Mechanisms of neurokinin A- and substance P-induced contractions in rat detrusor smooth muscle in vitro. BJUInt. 2004;94:651-7.

20. Fathian-Sabet B, Bloch W, Klotz T, et al. Localization of constitutive nitric oxide synthase isoforms and the nitric oxide target enzyme soluble guanylyl cyclase in the human bladder. JUrol. 2001;165:1724-9.

21. Andersson K-E. Agents in early development for treatment of bladder dysfunction-promise of drugs acting at TRP channels? Expert Opin Investig Drugs. 2019;28:749-55.

22. Charrua A, Matos R, Oliveira R, Marczylo T, Nagy I, Cruz F. Fatty acid amide hydrolase inhibition normalises blad- der function and reduces pain through normalising the anandamide/palmitoylethanolamine ratio in the inflamed bladder of rats. Naunyn Schmiedebergs Arch Pharmacol. 2020;393:263-72.

23. Rosa GM, Baccino D, Valbusa A, et al. Cardiovascular effects of antimuscarinic agents and $\beta 3$-adrenergic receptor agonist for the treatment of overactive bladder. Expert Opin Drug Saf. 2018;17:487-97.

24. Müderrisoglu AE, Becher KF, Madersbacher S, Michel MC. Cognitive and mood side effects of lower urinary tract medication. Expert Opin Drug Saf. 2019;18:915-23.

25. Fox C, Smith T, Maidment I, et al. Effect of medications with anti-cholinergic properties on cognitivefunction, delirium, physical function and mortality: a systematic review. Age Ageing. 2014;43:604-15.

26. Chapple CR, Kaplan SA, Mitcheson D, et al. Randomized double-blind, active-controlled phase 3 study to assess 12-month safety and effiaccy of mirabegron, a $\beta 3$ adrenoceptor agonist, in overactive bladder. Eur Urol. 2013;63:296-305.

27 . Michel MC, Gravas S. Safety and tolerability of $\beta 3$-adrenoceptor agonists in the treatment of overactive bladder syndrome-insight from transcriptosome and experimental studies. Expert Opin Drug Saf. 2016;15:647-57.

28. Haylen BT, Ridder D de, Freeman RM, et al. An International Urogynecological Association (IUGA)/International Continence Society (ICS) joint report on the terminology for female pelvic floor dysfunction. Neurourol Urodyn. 2010;29:4-20.

29. D'Ancona C, Haylen B, Oelke M, et al. The International Continence Society (ICS) report on the terminology for adult male lower urinary tract and pelvic floor symptoms and dysfunction. Neurourol Urodyn. 2019;38:433-77.

30. Michel MC, Oelke M, Goepel M, Beck E, Burkart M. Relationships among symptoms, bother, and treatment satisfaction in overactive bladder patients. Neurourol Urodyn. 2007;26:190-5.

31. Hashim H, Abrams P. Desmopressin for the treatment of adult nocturia. Therapy. 2008;5:667-83. 